STUDI

FRANCESI

\section{Studi Francesi}

Rivista quadrimestrale fondata da Franco Simone

186 (LXII | III) | 2018

Varia

\title{
ROSANNA GORRIS CAMOS, Les éditions turinoises des «Histoires tragiques». La Famille Farina et son secret
}

\section{Filippo Fassina}

\section{OpenEdition}

\section{Journals}

\section{Edizione digitale}

URL: http://journals.openedition.org/studifrancesi/15042

DOI: 10.4000/studifrancesi. 15042

ISSN: 2421-5856

\section{Editore}

Rosenberg \& Sellier

\section{Edizione cartacea}

Data di pubblicazione: 1 décembre 2018

Paginazione: 484-485

ISSN: 0039-2944

\section{Notizia bibliografica digitale}

Filippo Fassina, «Rosanna gorRIS camos, Les éditions turinoises des «Histoires tragiques». La Famille Farina et son secret», Studi Francesi [Online], 186 (LXII | III) | 2018, online dal 01 janvier 2019, consultato il 07 janvier 2021. URL: http://journals.openedition.org/studifrancesi/15042 ; DOI: https://doi.org/10.4000/ studifrancesi. 15042

Questo documento è stato generato automaticamente il 7 janvier 2021.

\section{(c) (i) (9)}

Studi Francesi è distribuita con Licenza Creative Commons Attribuzione - Non commerciale - Non opere derivate 4.0 Internazionale. 


\title{
ROSANNA GORRIS CAMOS, Les éditions turinoises des «Histoires tragiques». La Famille Farina et son secret
}

\author{
Filippo Fassina
}

\section{NOTIZIA}

ROSANNA GORRIS CAMOS, Les éditions turinoises des «Histoires tragiques». La Famille Farina et son secret, in Les Histoires tragiques du xvie siècle. Pierre Boaistuau et ses émules, sous la direction de Jean-Claude Arnould, Paris, Classiques Garnier, 2017, pp. 39-68.

Questo lavoro indaga in modo dettagliato e approfondito su alcuni libri appartenuti alla biblioteca di Margherita di Francia: la collezione delle Histoires tragiques, conservata nella Biblioteca Reale di Torino e pubblicata dalla famiglia di editori torinesi Farina. Si tratta della traduzione francese, a opera di Pierre Boaistuau e di François de Belleforest, delle novelle di Matteo Bandello, il cui legame con Margherita è qui ripercorso a partire dalla dedica della sua traduzione dell'Ecuba del 1538 e di un canzoniere del 1544 (Alcuni Fragmenti de le rime), conservato nella Biblioteca Nazionale di Torino e purtroppo bruciato nell'incendio del 1904. In virtù di questo legame, dopo la morte di Bandello, Margherita ha patrocinato la pubblicazione, tra il 1569 e il 1571 presso gli editori Cesare e Girolamo Farina, da sempre al servizio della sua corte, dei quattro tomi di queste histoires. Del resto, la passione di Margherita per le storie tragiche e per la letteratura etica è nota, come dimostra il paratesto del IV tomo, in cui si legge: «l'histoire tragique a surtout la fonction de montrer aux lecteurs les dangers et 'estranges traits' des passions destructrices, l'amour et l'ambition surtout» (p. 52). Eugénie Droz supponeva, tuttavia, che il nome dei Farina fosse un falso e che questi editori non fossero mai esistiti, mentre il saggio di R. Gorris, basandosi su dati concreti sia storici sia editoriali, intende dimostrare il contrario, confermando la tesi proposta da Michel Simonin. L'A. traccia infatti un dettagliato resoconto della storia e degli eventi più importanti relativi 
a questi editori e al loro rapporto con la corte di Margherita. Rapporto che tuttavia viene turbato dall'arresto, nel 1569, di Cesare Farina, accusato dalle autorità religiose di aver pubblicato opere interdette in quanto protestanti. Sembra tuttavia che l'editore abbia potuto continuare la sua attività, come dimostra il fatto che le edizioni delle Histoires degli anni 1574-1585 portano ancora il suo nome, anche se alcune di queste sono pubblicate a Lione e non a Torino. Con buona probabilità, Cesare, in seguito all'arresto, si recò a Lione, ma la famiglia Farina continuò a mantenere sia la sede italiana sia quella francese, secondo una consuetudine tipica di molte famiglie editrici cinquecentesche. Anche il fatto che il quarto tomo delle Histoires sia stato pubblicato a nome di Girolamo Farina è forse da ricondurre alle difficoltà incontrate da Cesare in quegli anni. Le informazioni storiche ed editoriali riportate in questo saggio permettono dunque di dimostrare l'esistenza della famiglia di editori Farina e il rapporto di collaborazione fra questa e la corte di Margherita e supportano, attraverso un vasto repertorio di analisi documentarie, l'idea di Simonin, secondo il quale i fratelli Farina erano «loin d'être imaginaires». 